\title{
EDITORIAL. CEAS 50 ANOS: EM TEMPOS SOMBRIOS, TECEMOS ESPERANÇA
}

Editorial. CEAS's 50 years: In dismal times, we weave hope

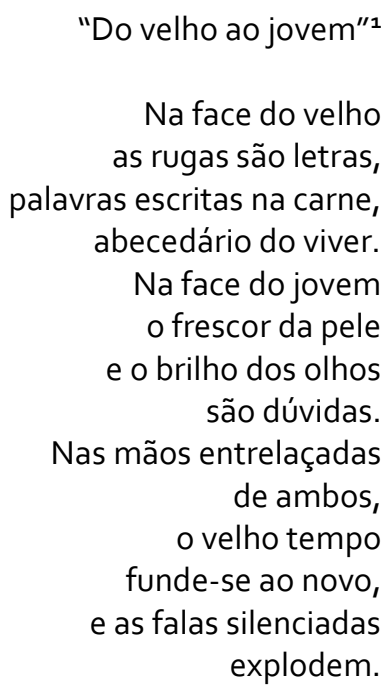

Saudoso e saudável. Assim, há 25 anos, o editorial comemorativo ao primeiro quarto de século do CEAS se referia à entidade criada em 1967 pelos jesuítas e que se tornaria uma referência da luta pela redemocratização do Brasil para religiosos e não religiosos. Mas um quarto de século depois, outro não é o estado do Centro, senão bastante saudável, em que pese as contínuas ameaças à democracia, aos direitos sociais e aos sujeitos históricos populares, que fazem com que este Centro procure reinventar-se a cada contexto, a cada virada histórica. Talvez por isso, os integrantes atuais e passados das suas equipes continuam a afirmar: podemos sair do CEAS, mas ele nunca sai de nós. Seguramente que sim, sobretudo se não perdemos a capacidade de nos indignarmos contra as injustiças e opressões de toda sorte.

Desse modo, chegamos, o CEAS a 50 anos e os Cadernos do CEAS a 48 anos. Idade da inovação, idade de se perseguir os caminhos da transformação, da revolução, cada vez mais necessárias para impedir a destruição da educação pública, da universidade e da pesquisa científica brasileiras, dos direitos sociais do campo e da cidade, em curso acelerado pelas forças retrógradas deste país.

\footnotetext{
${ }^{1}$ EVARISTO, Conceição. Em Poemas da recordação e outros movimentos. Belo Horizonte: Nandyala, 2008.
} 
Este projeto do atraso, porém, não representa o fim da história. Sua antítese já se esboça no nevoeiro da conjuntura. Como Bertold Brecht, no CEAS se crê que nos becos sem saída se encontram os caminhos da transformação. Suas equipes, urbana, rural, revista, memória e formação não largam as veredas do fortalecimento da luta popular.

No campo, caminha-se por consolidar as conquistas territoriais ameaçadas, incorporando mecanismos de reprodução social e sucessão geracional dos camponeses, via fortalecimento da produção, pela agrotransformação artesanal e comercialização agrícola e por mecanismos de acesso direto aos mercados consumidores local, regional e institucional; consolidando os territórios alcançados, mas sem perder de vista a ampliação da luta pela terra e a superação das injustiças no campo.

$\mathrm{Na}$ cidade, onde as injustiças são mais visíveis, as trilhas de superação das desigualdades não são tão nítidas. Isso, entretanto, não impede ao CEAS de prosseguir na luta por moradia digna, pela organização das comunidades periféricas, onde mulheres e a juventude animam e reanimam a todas as consciências que não admitem sucumbir ao racismo, a desigualdade social, ao machismo e a quaisquer outras formas de opressão.

Resistir ou resistir, não existe outra alternativa aos pobres da cidade e do campo. A partir dos 50 anos de existência do CEAS, podemos afirmar: outra opção não se coloca para os próximos cinquenta. Por isso, em tempos sombrios, tecemos a esperança ao lado dos sujeitos que podem mudar a realidade social brasileira.

Todavia, o desafio é dos mais complexos. Ainda mais numa sociedade dominada pelo oligopólio da comunicação e, portanto, de produção de identidades cultural e política coletivas. Nesse contexto, é relevante a iniciativa de organização do centro da memória social do trabalho no CEAS, articulado a um plano estratégico para as próximas décadas de construção de mecanismos de informação voltados aos setores e movimentos sociais populares.

Para tudo isso, uma condição é fundamental: o diálogo entre saberes. A pesquisa científica, acadêmica, a cultura e o conhecimento dos povos do campo e da cidade em permanente interação, eis a missão desses Cadernos, que se renova nessa conjuntura de sombras.

Numa edição comemorativa, e na conjuntura que atravessamos, não poderíamos prescindir de um olhar retrospectivo sobre a história de resistência dos setores democráticos brasileiros. Em A atuação do CEAS durante a ditadura militar, o sociólogo Joviniano Neto 
aborda alguns desses segmentos para traçar um quadro do trabalho realizado nos difíceis anos 70 e 80 do século passado. Nesta releitura histórica, o autor destaca o papel desempenhado pelos Cadernos do CEAS, por este Centro e pelos grupos com quem estes se relacionavam durante a ditadura civil militar, analisando as características da atuação social no contexto de supressão das liberdades democráticas, entre 1969 e 1984. Usando os acervos da ditadura já disponíveis no Arquivo Nacional (RJ), do CEAS e também as suas próprias memórias, o autor resgata a relevância histórica e política desta publicação, avançando para demonstrar, ainda, a dimensão social do trabalho organizativo realizado por esses e outros grupos junto aos favelados da cidade do Salvador e junto aos assalariados e trabalhadores do cacau e do café, respectivamente, nas regiões sul e sudoestes baianas, além dos trabalhadores da cana-de-açúcar na zona da Mata de Alagoas e Pernambuco. Como "palavras escritas na carne", não escapa à analise a dimensão repressiva do regime em face do trabalho social e intelectual que se expressava através desses Cadernos, demonstrada pela análise dos inquéritos e processos judiciais que visaram a deportar alguns dos integrantes do CEAS e membros da Ordem dos Jesuítas.

Mantendo sua preocupação com as raízes agrárias do poder e do próprio capitalismo no Brasil, esta edição, em Governo Temer: Relações do agronegócio com o capital especulativo financeiro e impactos sobre os camponeses e a legislação agrária, retoma a discussão sobre as tendências mais recentes do desenvolvimento rural brasileiro. Neste artigo, Joaci de S. Cunha, coeditor deste periódico, discute as ações político-legais do governo de Michel Temer direcionadas ao setor agrário, bem como suas consequências sobre os camponeses e os povos do campo. Para o autor, nessas ações oficiais, destacam-se a desestruturação da política pública de reforma agrária; a aprovação de lei que permite a transformação em propriedade privada as áreas rurais e urbanas de domínio público em todo o país; e, a proposta que pretende facilitar a estrangeirização da propriedade dos imóveis rurais de Norte a Sul do território nacional. Em sua análise, esses projetos correspondem aos interesses na só do governo, mas principalmente dos setores ligados ao agronegócio latifundiário e ao capital financeiro especulativo. Como consequência dessas tendências, vislumbra o crescimento da grande propriedade, a violência sobre os povos tradicionais do campo, e, como "explosão das falas silenciadas", propugna o autor por uma urgente reação da sociedade e das organizações camponesas num esforço nacional de resistência. 
Resistência essa que Bruna Muriel identifica na luta dos povos indígenas sulamericanos em defesa dos seus modos de vida e territórios. Apresentando os resultados parciais da sua pesquisa de pós-doutorado junto ao Programa de Pós-Graduação em Relações Internacionais do Instituto Interdisciplinar de Humanidades, Artes e Ciências da Universidade Federal da Bahia, a autora indica o estado dessas lutas cada vez mais articulado internacionalmente.

Assim, em Os povos indígenas da América do Sul: entre a IIRSA e o buen vivir, o leitor desses Cadernos observará, como, em nosso subcontinente, as organizações indígenas têmse organizado regionalmente, os seus modos de resistirem aos impactos ambientais e sociais dos megaempreendimentos ligados à Iniciativa para a Integração da Infraestrutura Regional Sul-americana (IIRSA), da China em parceria com Estados sul-americanos, que visa facilitar o escoamento pelo Pacífico de commodities sul-americanas e de manufaturados chineses para a região. Além disso, esse artigo examina, em que medida o conceito filosófico e projeto político-civilizatório do Buen Vivir - que ganhou visibilidade com as mobilizações sociais encabeçadas pelos movimentos indígenas equatorianos e bolivianos no início desse século - vem sendo incorporado à retórica e à luta dessas organizações no contexto da IIRSA.

Nessa trilha, a autora realiza uma contribuição relevante ao debate sobre o modelo de desenvolvimento intrínseco às políticas nacionais e aos projetos de integração regional. Da mesma forma, sua investigação aponta para uma agenda política mais afinada com as demandas dos povos indígenas e com a proteção da natureza. Por aí, de "mãos entrelaçadas", Brasil e América Latina poderão tirar importantes lições dessas experiências.

$\mathrm{Na}$ toada das abordagens regionalizadas, a edição segue com a análise do modelo de desenvolvimento sul-americano. No artigo Capital estrangeiro e conflitos socioambientais em torno das riquezas minerais..., assinado por Diego Jesus da Silva e Gilca Garcia de Oliveira, temos a análise do processo de acumulação do capital a partir de exploração das riquezas minerais do espaço sul-americano e os conflitos dela decorrentes, sobretudo aqueles ocorridos nos anos 2000. Os autores analisam o papel do capital estrangeiro e como o avanço dos seus fluxos vem reforçando a condição dependente dos países do subcontinente, reforçando neles a condição de fornecedores de mercadorias de baixo valor agregado no âmbito da divisão mundial do trabalho.

Na exposição, fica evidenciado como a exploração dos recursos minerais vem sendo conduzida a partir dos ditames do capitalismo global, via investimentos estrangeiros diretos 
(IEDs), e como esse processo tem orientado a economia política do subcontinente no sentido de reforçar a sua dependência em face dos centros mundiais do poder. Sobressaem, no artigo, as implicações desse modelo, como o crescimento dos conflitos socioambientais, impulsionando movimentos populares a lutarem contra a espoliação capitalista que atinge distintos setores sociais e a natureza.

Enfim, "na face do velho", a edição 241 vem esculpindo "rugas" diversas, que marcam seus textos conforme os conceitos - ferramentas adotados. Por certo, essa imagem inspirada na poetisa Conceição Macedo, também se aplica à leitura do contexto geopolítico mundial. E numa perspectiva simbólica, assim podemos ler o artigo BRICS: Um balanço crítico, escrito por Ana Elisa Saggioro Garcia.

Surgido a partir de conferências internacionais no início deste século, os BRICS ganharam importância política e econômica após a crise mundial de 2008, quando passaram a ser vistos como um polo alternativo à hegemonia dos EUA e da Europa. Nesse artigo, todavia, a autora questiona o suposto papel contra hegemônico dos BRICS. Para a professora do Departamento de História e Relações Internacionais na Universidade Federal Rural do Rio de Janeiro (UFRRJ), em termos políticos, a agenda dos BRICS não vem sendo de confrontação do poder hegemônico, mas sim a de reivindicar "um lugar à mesa" junto às potências ocidentais. Enfim, China, Rússia, Índia, Brasil e África do Sul buscam um lugar apropriado à sua dimensão econômica nas instâncias de concerto global.

De todo modo, iniciativas como a de criação do Novo Banco de Desenvolvimento e uma política de cooperação internacional diferenciada em relação àquela de condicionamentos políticos e econômicos de inspiração neoliberal do FMI e do Banco Mundial, representam pontos claros de disputa entre os BRICS e estes polos de poder tradicionais, sobretudo na África e na América Latina. Mas isso está longe de significar uma real alternativa para uma ordem mundial mais justa. Além disso, entre os países membros, existem não só convergências. As próprias relações entre os BRICS e deles com outros países do Sul global se inserem num quadro mais amplo de acumulação capitalista e respondem a uma lógica de disputas por recursos naturais, acesso a mercados e mão de obra barata, além claro das mudanças políticas internas a cada país, a exemplo do Brasil, que podem impactar na unidade de propósitos entre eles.

Por isso mesmo, um desafio central, exigindo "brilho dos olhos", continua sendo a articulação de lutas sociais desde baixo: camponeses e trabalhadores que enfrentam e 
resistem em seus territórios a grandes projetos de países BRICS (ou não) e suas instituições financeiras.

Noutra vertente de entendimento, no artigo Uma visão crítica da cooperação Sul-Sul: Práticas, atores e narrativas, Enara Echart Muñoz, professora adjunta da Escola de Ciência Política da Universidade Federal do Estado do Rio de Janeiro (UNIRIO), constata que o ressurgimento das práticas de cooperação Sul-Sul na última década gerou um intenso otimismo sobre as novas formas de cooperação para o desenvolvimento; e também um debate sobre em que medida estas práticas realmente redimensionam o panorama internacional, alteram as relações Norte-Sul e oferecem novas solidariedades e oportunidades de desenvolvimento.

Neste artigo, ela contrapõe o "sistema internacional de cooperação para o desenvolvimento" ao espírito da Conferência de Bandung (de 1955), onde países asiáticos e africanos - muitos deles recém-independentes - reuniram-se para firmar as bases de uma cooperação entre os países do Sul frente ao poder do Norte, inspirada pelos princípios do respeito aos direitos fundamentais, à soberania e à integridade territorial de todas as nações; a igualdade de todas as raças e de todas as nações; não-intervenção e não-ingerência em assuntos internos; promoção do interesse e da cooperação recíproca; e respeito pela justiça e pelas obrigações internacionais. Enquanto isso, o "sistema internacional de cooperação" pode ser visto como um espaço de geração de consensos necessários à hegemonia, à aceitação social da ordem, o que requer, por parte das forças hegemônicas, uma estratégia de assimilação, cooptação e domesticação de ideias contra hegemônicas dos grupos subalternos, ajustando-as a políticas da coalizão dominante. Para isto, portanto, são fundamentais as concessões possibilitadas por esse tipo de cooperação. O sistema de cooperação, por conseguinte permitiria outra forma de diminuição de desigualdades, menos ameaçadoras para o sistema.

Em sua abordagem, a autora parte da cooperação Sul-Sul (CSS) brasileira como exemplo para analisar criticamente as disputas e os sentidos da cooperação no tocante às práticas, aos atores e às narrativas em torno ao desenvolvimento. Para isso, a autora entende ser insuficiente entender essa cooperação internacional unicamente a partir da análise da política externa, considerando não somente o seu conjunto de atores, instituições e normas, mas também a ação de legitimação da hegemonia na atual ordem global. Para ela, o espaço 
internacional parece estar aberto a vozes mais plurais, mas boa parte dos países e povos do Sul ainda permanecem excluídos dos principais debates e instituições.

Nessa linha de análise, Tiago Nery, em Política externa brasileira, modelo de desenvolvimento e coalizões políticas, analisa, historicamente, as relações entre a política externa brasileira, o modelo de desenvolvimento econômico e as coalizões políticas entre 1930 e 2016. Inicialmente, destaca ele a importância da dimensão doméstica da política externa (afirmando sua influência sobre as demais políticas públicas), condicionada por valores de diferentes atores, a exemplo dos partidos políticos, para, em seguida, discutir duas ideias-força que caracterizaram a política externa brasileira: a autonomia e o desenvolvimento. Apesar da importância de ambas, durante o período nacionaldesenvolvimentismo a busca do desenvolvimento tornou-se o principal vetor da política exterior do país. Na sequência, o autor, que é doutor em Ciência Política pelo Instituto de Estudos Sociais e Políticos da Universidade do Estado do Rio de Janeiro (IESP-UERJ), analisa o governo Fernando Henrique Cardoso, destacando as relações entre as reformas econômicas, a coalizão política e a política externa. Por fim, são analisados os governos Lula da Silva e Dilma Rousseff (2003-2015), ambos do Partido dos Trabalhadores (PT). Para ele, os governos petistas se apoiaram em coalizões heterogêneas, ensaiaram uma política neodesenvolvimentista e adotaram uma política externa mais autônoma, ressaltando a influência desse modelo de desenvolvimento nas coalizões políticas que marcaram a política externa brasileira desse período.

A análise dos últimos anos das relações políticas e econômicas entre o Brasil e os países africanos, encontramos em Do outro lado do Atlântico: As relações políticas e econômicas entre o Brasil e os países africanos desde o século $X X$, que na metáfora poética que nos acompanha poderia ser lido como "na face do jovem, o frescor da pele ... dúvidas".

Neste artigo, Elga Lessa de Almeida mostra-nos como nessas relações ocorre a repetição de um certo padrão, presente ao longo de todo o século $X X$, que se configura por curtos períodos de aproximação seguidos por períodos maiores de afastamento. Desse modo, a autora, que é professora adjunta da Universidade Federal do Recôncavo da Bahia (UFRB), constata como a importância da herança africana para a formação da sociedade brasileira não tem se refletido na construção de relações estáveis com alguns desses países ou que se dinamizem e se aprofundem ao longo do tempo. 
Para a autora, durante o governo de Lula da Silva, adotou-se o princípio da solidariedade Sul-Sul e a ideia da existência de uma dívida histórica com o continente. Por esse caminho, a relação teria sido ampliada e menos pragmática. Ao lado de grandes investimentos brasileiros e considerável aumento das trocas comerciais no período, também foram realizados projetos de cooperação técnica. Considera que, apesar das críticas ao conteúdo de alguns desses projetos - especialmente, o ProSavana, levando o agronegócio empresarial para o território dos camponeses africanos -, a política desse período possibilitou a realização de importantes ações, como a construção da fábrica de medicamentos antirretrovirais em Moçambique e a intensificação da cooperação na área educacional, com a criação da Universidade da Integração Internacional da Lusofonia Afro-brasileira - UNILAB. Todavia, essa política teria sido parcialmente abandonada pelo governo de Dilma Rousseff e, com Temer, apresenta-se absolutamente contrária às diretrizes anteriores.

A África continua em nossas páginas, agora através de Os heróis que detestavam quem eles deveriam salvar: O paradoxo identitário das crianças-soldados na guerra de Serra Leoa. Neste belo artigo, Breno Fernandes, jornalista, que também é mestre em Relações Internacionais e realiza doutoramento em Literatura \& Cultura (UFBA), parte da leitura de "Muito longe de casa: memórias de um menino-soldado", romance autobiográfico de Ishmael Beah, narrando sua experiência como criança-soldado do exército de Serra Leoa durante a guerra civil do país (1991-2002), para refletir sobre as identidades que são construídas nessa vivência traumatizante. Um pequeno trecho:

\footnotetext{
"Estava claro pelo seu tom de voz que ele não me queria por perto e não confiava em mim [...] Eu estava feliz em ver outros rostos e ao mesmo tempo triste porque a guerra tinha destruído a alegria da experiência de conhecer gente. Não se podia mais confiar nem mesmo em um menino de doze anos".
}

Partindo do pressuposto de que a guerra civil trinca o discurso nacionalista, ao autor interessa verificar como essas identidades conformadas no cotidiano da guerra se articulam com a identidade nacional e a ressignificam. Nesse movimento, chama atenção o fato de o exército de Serra Leoa ter mobilizado garotos apelando a diversas identidades, inclusive à de heróis nacionais, mas obtendo como resultado final sujeitos que, na prática, detestavam os civis tanto, ou quase tanto, quanto desprezavam os rebeldes da Frente Revolucionária Unida (RUF). Sugere, por fim, que o desatamento desse emaranhado identitário engendrado pela guerra seja um dos fatores que determinariam o êxito das políticas de DDR — desarmamento, 
desmobilização e reintegração social — voltadas para as crianças-soldados, realizadas entre 1996 e 2002. Um êxito que para alguns analistas, todavia, não se verificou.

Em Revisión de la subjetividade laboral feminina em México, desde las tesis de la psicodinâmica del trabajo, Jose Juan Cervantes Niño, professor da Universidade Autónoma de Nuevo León (Monterrey, México), apresenta os resultados da sua pesquisa "Informalidad y mercados de trabajo en México 1995-2016: Reinterpretaciones e implicaciones para el desarrollo y crecimiento económico". Situado no campo do trabalho e subjetividade, este artigo usa os pressupostos da teoria psicodinâmica do trabalho, para estudar as mulheres empregadas nas áreas de limpeza.

Para esse autor, com a implementação do modelo neoliberal de desenvolvimento capitalista, a estrutura da economia mundial entrou numa fase de grandes transformações, que afetaram várias áreas de desenvolvimento. No campo dos mercados de trabalho, configurações típicas foram alteradas, impactado o emprego, os atores desses mercados e, assim, subvertendo as suas percepções de trabalho em vários níveis de subjetividade. Esse texto procura identificar, analisar e explicar uma série de estratégias (simbólicas) usadas na realização das atividades dessas mulheres. Estratégias essas que visam contornar o impacto negativo que altos níveis de insegurança e desigualdade causam em seu desenvolvimento profissional, pessoal e familiar, o que aparentemente as ajudariam a lidar com sua vida social em aparente harmonia. Noutro sentido, entende Jose Juan Niño, essas ações podem contribuir para perpetuar e manter a exploração que tradicionalmente sofre esse estrato social.

Encerrando essa edição, Mailson F. Cabral de Souza, em Direitos Humanos e diversidade religiosa... apresenta um breve itinerário da relação entre direitos humanos e diversidade religiosa no Brasil, a partir de um recorte no discurso político do Comitê Nacional de Respeito à Diversidade Religiosa (CNRDR). O autor, que é mestre em Ciências da Religião pela Universidade Católica de Pernambuco (UNICAP) e membro do Observatório Transdisciplinar das Religiões no Recife, procura explicar como se dá a relação entre religião e espaço público no cenário brasileiro.

A partir do discurso do CNRDR, são apresentadas as relações entre direitos humanos e diversidade religiosa, marcadas por uma dinâmica de contradição e de complementaridade. Por aí, conclui o autor que o CNRDR não possui um conceito de diversidade religiosa estabelecido, mas uma noção heterogênea e aberta, que, todavia permite a inserção da 
religião no âmbito das políticas públicas. Sob esse viés, considera ele, a diversidade religiosa pode representar um gesto de leitura para a compreensão dos embates ideológicos que acontecem na relação entre religião e política no espaço público brasileiro.

Ao apresentar esta edição, a revista Cadernos do CEAS tem o desejo sincero de que as palavras escritas na carne, como abecedário do viver, contribuam para forjar o tempo novo, através das contradições do velho-presente. Afinal, em tempos sombrios, tecemos esperanças.

Joaci de S. Cunha - Coeditor (CEAS - UCSal)

Catarina Lopes - Sec. Executiva (CEAS) 